Int. J. Electrochem. Sci., 15 (2020) 10157 - 10172

\title{
Influence of dodecyl sulfate anions doped hydroxide precursor on enhanced electrochemical properties of $\mathrm{LiNi}_{x} \mathrm{Co}_{y} \mathrm{Mn}_{1-x-y} \mathrm{O}_{2}$ as lithium-ion battery cathodes
}

\author{
Fanghui Tian ${ }^{1}$, Xuecheng Fan ${ }^{1}$, Qiang Wang ${ }^{2}$, Xiao Ouyang ${ }^{2, *}, H a o$ Wei $^{2}$, Qiang Shen ${ }^{1, *}$ \\ ${ }^{1}$ Key Laboratory for Colloid and Interface Chemistry of Education Ministry, School of Chemistry and \\ Chemical Engineering, Shandong University, Jinan 250100, China. \\ ${ }^{2}$ Key Laboratory of Superlight Material and Surface Technology of Education Ministry, College of \\ Material Science and Chemical Engineering, Harbin Engineering University, Harbin 150001, China. \\ *E-mail: qshen@sdu.edu.cn oyx1028@hrbeu.edu.cn
}

doi: $10.20964 / 2020.10 .24$

Received: 6 June 2020 / Accepted: 16 July 2020 / Published: 31 August 2020

\begin{abstract}
Lithium-containing nickel-cobalt-manganese ternary transition metal oxides (e.g., $\mathrm{LiNi}_{x} \mathrm{Co}_{y} \mathrm{Mn}_{1-x-y} \mathrm{O}_{2}$, abbreviated as NCM) may combine the lithium extraction/insertion advantages of $\mathrm{LiCoO}_{2}, \mathrm{LiNiO}_{2}$ and $\mathrm{LiMnO}_{2}$ "single-component" cathode materials because of a well-known synergistic effect at the optimal Ni:Co:Mn molar ratio of 1:1:1. This paper deals with optimized preparation and enhanced electrochemical properties of $\mathrm{LiNi}_{x} \mathrm{Co}_{y} \mathrm{Mn}_{1-x-y} \mathrm{O}_{2}$ cathode material modified by the addition of anionic surfactant (i.e., sodium dodecyl sulfate SDS) into the hydroxide-precursor precipitation system of equimolar-ratio divalent transition metal sulfates. In the absence and presence of additive SDS, the finally resulting products of NCM and SDS-NCM show the leakage of elemental Co in each formula $\mathrm{LiNi}_{x} \mathrm{Co}_{y} \mathrm{Mn}_{1-x-y} \mathrm{O}_{2}$, and their crystallites possess an average particle size of $450 \pm 100$ and $250 \pm 40 \mathrm{~nm}$, respectively. This modification makes a relatively high $\mathrm{SO}_{4}{ }^{2-}$ content in SDS-NCM with the better electrochemical properties (e.g., capacity $\sim 135.4 \mathrm{mAh} \mathrm{g}^{-1}$, at $20 \mathrm{~mA} \mathrm{~g}^{-1}$, in the 150th cycle) than those of NCM (capacity $293.8 \mathrm{mAh} \mathrm{g}^{-1}$, at $20 \mathrm{~mA} \mathrm{~g}^{-1}$, in the 150th cycle). In a word, both the structure optimization and performance-enhanced mechanism of SDS-NCM are discussed in detail in context.
\end{abstract}

Keywords: Ternary transition metal hydroxide, anionic surfactant, cathode, lithium-ion batteries.

\section{FULL TEXT}

(C) 2020 The Authors. Published by ESG (www.electrochemsci.org). This article is an open access article distributed under the terms and conditions of the Creative Commons Attribution license (http://creativecommons.org/licenses/by/4.0/). 